\title{
Study on Performance Evaluation of Government Comprehensive Supervision for Safety Production Based on Balanced Score Card --- A Case Study in Shandong Province, China
}

\author{
$\mathrm{Hao} \mathrm{Yu}^{1,2}$ \\ ${ }^{1}$ School of Emergency Management, Henan Polytechnic University, Jiaozuo 454000, Henan, China \\ ${ }^{2}$ China University of Geosciences (Beijing), Beijing 100083, China \\ E-mail:haoyu_he@163.com \\ Received 16 March 2016
}

Accepted 2 May 2016

\begin{abstract}
The government supervision is the key to guarantee work safety. In order to improve the level of safety production supervision of the government, a performance evaluation indicator system of safety production supervision within city and county two levels for the local government has been established according to the theory of key performance indicators. 4 first-level indicators and 40 secondary indicators have been designed. The weight of these indicators has been determined by using the analytic hierarchy process and Delphi method. This study may contribute to providing management tools and ideas for the local government performance evaluation on the supervision safety production in China.
\end{abstract}

Keywords: Local government, Safety production supervision, Performance evaluation, Indicator system

\section{Introduction}

Safety production is a sign of social civilization progress, and an important booster to promote the economic transformation and upgrading. In recent years, there are a large number of safety accidents in China. From the start of 2015, all kinds of safety accidents have occurred frequently, Shanghai bund stampede is heart-wrenching, then Harbin "1.2" fire accident, Shaanxi Xianyang "5.15" traffic accident, Henan Pingdingshan "5.25" fire accident, and "Oriental Star" passenger ship capsized accident is still a painful accident. The frequent occurrence of these accidents brings huge pain and sufferings to people, at the same time, the social economic construction and national development also suffer. To find an effective way to prevent these safety accidents, the government and all relevant personnel have made great efforts, especially in the regulation of work safety. The frequent safety accidents are related to less attention to safety production, lacking in the designated position and malfeasance behaviors of individual officials with the value orientation of local government centering on GDP. With the purpose of changing the status quo of safety production in China, the State Council of China adopted various measures to improve the efficiency for regulation and administration on safety production each level of government, the introduction of the performance management is one of the important measures.

An effective method of performance management is the implementation of performance assessment, namely test and evaluation are carried out to the supervision of relevant government departments by using targeted indicators or standards. And through the results of the evaluation, the shortages of government are reflected to guide the government supervision in the future. So, establishing a scientific and practical government performance evaluation system of safety production supervision is the long-term effective measure to improve the efficiency of safety production.

As to the world recognized difficult problem of government performance evaluation, evaluation indicator system design is arguably one of the difficulties on account of the wide scope of the government activities, complex process and the complicated factors. Although the domestic academic circles have a lot of research on 
government performance evaluation, a set of widely accepted indicator system still does not appear, and practicality is poor. In terms of performance evaluation of government regulation and work safety, in recent years, some scholars and experts have made some relevant research on the performance evaluation of safety production supervision, and established relevant indicator systems, however, in view of the local government overall performance evaluation of safety production supervision, few scholars designed the concerned indicator system. Therefore, this study intends to explore the local government performance evaluation system of safety production supervision, combined the predecessors' research results and practical investigation, a set of assessment system applicable to the city (county) level is developed, namely (city) county safety production supervision performance evaluation indicator system, and then the related processes for implementation evaluation is discussed. This study may offer scientific theory and method, reasonable and effective tools and methods for performance evaluation work for the government safety production comprehensive supervision, which can improve safety production supervision performance of the government and then improve the overall efficiency.

In this study, on-the-spot investigation method is adopted, including interview and questionnaire survey. Interview survey's goal is to define the job requirements, difficulties and problems of the government in the supervision of safety production and the survey can provide material and basis. This study uses interview method, according to the experiences of previous evaluation of relevant experts in Tai'an city government; the filtered set indicator in the first round is amended, but only the secondary indicators change, the first-level indicators remain unchanged. In this case, the second round evaluation indicator of the performance evaluation of safety production supervision for local government is made sure. Questionnaire survey method is to use special questionnaires, questionnaire of second round indicator will be distributed to the Tai'an concerned municipal government departments, and eligible staff information, instructions on the use of the questionnaire and evaluation indicator are listed in the questionnaire. Tai' an is a city of Shandong Province, China. Simple words are used to explain the meaning of each indicator, and Tai' an municipal government departments are organized to fill in the investigators, some advice is collected, and then the evaluation indicator system is determined, at last the reasonable feasibility is verified. 21 questionnaires are distributed to Tai'an government, 15 questionnaires are distributed to Tai'an administration of work safety, 15 questionnaires are distributed to each of the four subordinate areas and 85 effective questionnaires are taken back to determine the final result

\section{The framework of performance evaluation indicator system of work safety regulation for the local government}

\subsection{The strategy map of local government work safety regulation}

Balanced Score Card (BSC) is proposed by Robert S. Kaplan and David P. Norton in the United States in 1992, which is the latest and the most comprehensive in theory and method of enterprise performance management at present. This method decomposes the enterprise strategic target to layers, and finally into a variety of detailed, balanced performance evaluation system for each other, from the financial performance, business process, innovation and growth, customer satisfaction four dimensions, a benign PDCA circulation is formed. This study tries to build a performance evaluation system of safety regulation for the local government under the framework of BSC (six factors and four dimensions), based on the SMART principles of key performance indicators (KPI). Four dimensions of safety regulation performance management for the local government are shown in Fig. 1.

A clear and complete safety strategy map is the beginning of sound cycle of safety regulation performance management for local government. According to the safety strategy map, this research designs indicators of safety production supervision performance for local government based on KPI theory. And SMART principle is the KPI setting criterion, namely each selection for indicator of the system should follow the principle of SMART principles, five basic principles are shown in Table 1. 


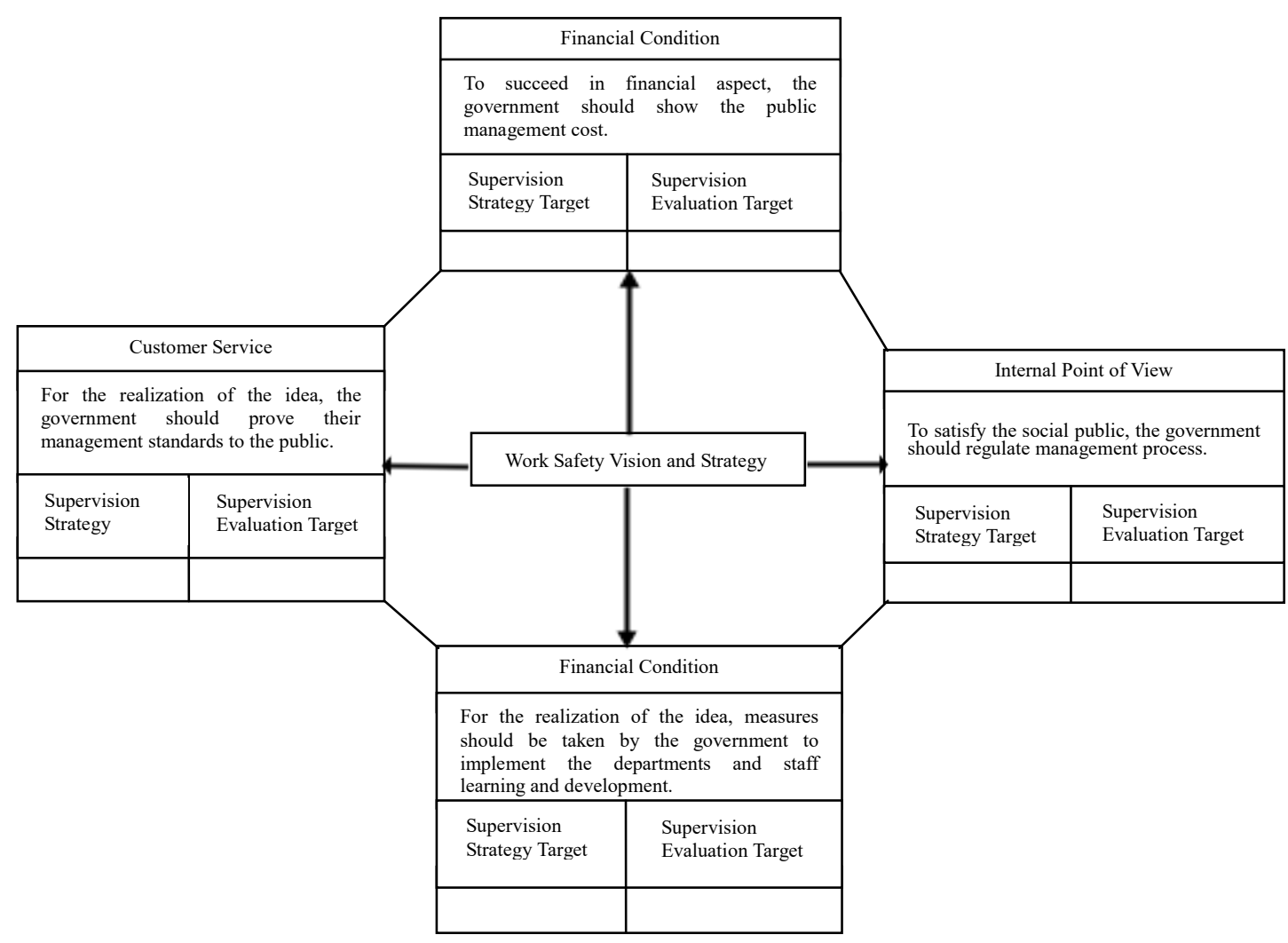

Fig. 1. Four dimensions relationship of safety regulation performance management

Table 1. SMART Principles

\begin{tabular}{|l|l|}
\hline S (Specific) principle & $\begin{array}{l}\text { All key performance indicators are to clearly describe the required action plans } \\
\text { completed by the evaluation main body and object. }\end{array}$ \\
\hline M (Measurable) principle & $\begin{array}{l}\text { Key performance indicators should be quantified as much as possible; there should } \\
\text { be quantitative data, such as quantity, quality, and time and so on, which can be } \\
\text { measured objectively. }\end{array}$ \\
\hline A (Attainable) principle & $\begin{array}{l}\text { Two aspects: First, the quota is moderate and reasonable, which is on the premise } \\
\text { of consensus between the superior and lower level, in government departments, } \\
\text { and the government departments and enterprises can control the scope of the task; } \\
\text { Second, the target must be "after a certain effort" to implement, and not just repeat } \\
\text { the target before. }\end{array}$ \\
\hline R (Relevant) principle & $\begin{array}{l}\text { Two aspects: First, superior objectives must be set before the lower targets, and } \\
\text { they have consistency, avoid repeating or target fault; Second, staff's KPI target is } \\
\text { associated with individual main job duties within the team. }\end{array}$ \\
\hline T (Time-bound) principle & There is no difference between the targets without time limits and no targets. \\
\hline
\end{tabular}

\subsection{Performance Evaluation indicator System of Work Safety Regulation for the Local Government}

Safety production supervision process is a complex multi-factor, multi-variable, multi-level system, with complicated process and related factors, and for a long time, it is always difficult to take quantitative analysis. Therefore, comprehensive consideration of various factors must be in the process of selection for performance evaluation indicator of government safety production supervision because the selected indicators accuracy will directly affect the measurement result. Not only that, the design of the indicator weight is also very important, if the weights are designed not reasonable, the assessment result is also biased.

Safety production Law of the People's Republic of China (amendment) came into force on December 1 last year, of which a mechanism 
of five parties including the responsibilities of business entities, participation of employees, governmental supervision, industry selfregulation, and supervision from the general public shall be established, and also powers and duties the government safety administrative departments at all levels should conduct are defined. So, the establishment of performance evaluation indicator system of safety production supervision for local government must be closely around the regulation content. This study integrates performance, government performance and the government safety production supervision relevant research results both at home and abroad, combines with Shandong province and Tai'an city issued XXXX Annual Safety Production, Safety Production Target Responsibility Appraisal Score Detailed Rules and other Tai'an city government relevant documents, four first-level indicators to the performance measurement are determined, thus the first round of the evaluation indicator system is preliminarily determined. In addition, the government performance evaluation's goal is to complete an organic integration and equilibrium of government democratic administration and administrative efficiency, the government must pay attention to public participation, satisfaction with citizens and businesses and the opinions and suggestions should be reflected, and government behavior can be effectively supervised, to make the government in the process of resource management to achieve transparent and open. Therefore, according to the actual situation of work safety regulation performance evaluation of the government, eligible persons, and the characteristics of public participation, under the condition of Tai'an city government officials advising, secondary indicators are divided into the following three types of properties: (1) Safety administration statistics confirm type: The assessment team conducts research, collects data for the head of the whole performance evaluation, then the head checks out the points; (2) Assessment group evaluation type: Different assessment groups are organized, do research and give a mark for different industries and departments, and the indicators are achieved by model calculation; (3) Public comment type: Enterprises and citizens are organized to fill in the questionnaire survey and give advice, to the end of the test, evaluation software will process the questionnaires to get the results of corresponding indicators. Indicator system includes four first-level indicators: the construction of the supervision base, execution building, administrative efficiency and supervisory effect. (4) first-level indicators are divided into 40 secondary indicators. The design idea is: emphasis on micro aspect, on-site supervision function, highlighting the base and execution construction, attaching great importance to the administrative efficiency and the supervisory effect. The performance evaluation indicators of government Safety Production are shown in Table 2. The comprehensive statistical results of indicators are shown in Table 3.

\section{Design and determining weight of the evaluation indicator}

The performance evaluation indicator system of safety production supervision for local government includes two levels: first-level indicators and secondary indicators, in the process of design weights, the weight score of secondary indicators should be 100 points. The analytic hierarchy process (AHP) is chosen to determine the weights of first-level indicators. AHP method was put forward by American professor Saaty, which is a practical method of making multiple criteria decision. AHP decomposes the complex problem to layers, forming a recursive class hierarchy; all the elements are compared in pairs to determine the relative importance of various factors in each hierarchy elements, and judgment matrix is built, the largest characteristic root and the corresponding eigenvector to the judgment matrix are calculated, then the factors' weights are achieved, on the basis of this, combination weights of each factor are calculated.

\subsection{The determination method of weight score for first-level indicator}

The process to determine the weights of first-level indicator according to the following steps to implement:

a) Four first-level indicators are compared in pairs; the design expert scoring tool table is shown in Table 4.

b) Constructing the judgment matrix Four first-level indicators are compared in pairs, and 
Table 2. The performance evaluation indicator system of safety production supervision for local government

\begin{tabular}{|c|c|c|}
\hline First-level indicator & Secondary indicator & Indicator type \\
\hline \multirow{8}{*}{$\begin{array}{l}\text { A. The construction of } \\
\text { the supervision base } \\
\text { (19) }\end{array}$} & A.1 Organizational architecture & Safety administrative statistics confirm type \\
\hline & A.2 Special fund & Safety administrative statistics confirm type \\
\hline & A.3 Regulatory funds and equipment & Safety administrative statistics confirm type \\
\hline & A.4 Regulatory team construction & Safety administrative statistics confirm type \\
\hline & A.5 Performing duties & Assessment group evaluation type \\
\hline & A.6 Enterprise standardization & Safety administrative statistics confirm type \\
\hline & A.7 Occupational hazards declaration & Safety administrative statistics confirm type \\
\hline & A.8 Activities establishment situation & Safety administrative statistics confirm type \\
\hline \multirow{21}{*}{$\begin{array}{l}\text { B. Executive force } \\
(53)\end{array}$} & B.1Conducting annual activities situation & Safety administrative statistics confirm type \\
\hline & B.2 Hold meetings situation & Safety administrative statistics confirm type \\
\hline & B.3 The responsibility system & Safety administrative statistics confirm type \\
\hline & B.4 Cadres performance evaluation & Safety administrative statistics confirm type \\
\hline & B.5Governance illegal rule violations & Assessment group evaluation type \\
\hline & B.6 Close enterprises situation & Assessment group evaluation type \\
\hline & B.7Major festivals and time arrangement & Safety administrative statistics confirm type \\
\hline & B.8 Special project rectification & Assessment group evaluation type \\
\hline & B.9 Work safety month & Safety administrative statistics confirm type \\
\hline & B.10 Safety culture propaganda & Safety administrative statistics confirm type \\
\hline & B.11 Employee training & Assessment group evaluation type \\
\hline & B.12Head,management personnel training & Assessment group evaluation type \\
\hline & B.13Emergency rescue command system & Safety administrative statistics confirm type \\
\hline & B.14 Contingency plan management & Safety administrative statistics confirm type \\
\hline & $\begin{array}{l}\text { B.15Work safety emergency information } \\
\text { construction and basic data updating }\end{array}$ & Safety administrative statistics confirm type \\
\hline & B.16 Law enforcement plan & Assessment group evaluation type \\
\hline & B.17 Dynamic regulation & Safety administrative statistics confirm type \\
\hline & B.18Supervising enterprises establishing rules & Assessment group evaluation type \\
\hline & $\begin{array}{l}\text { B.19Supervising institutions and the staff } \\
\text { setting of enterprises }\end{array}$ & Assessment group evaluation type \\
\hline & B.20Supervising enterprises safety costs & Assessment group evaluation type \\
\hline & B.21Yellow card warning & Safety administrative statistics confirm type \\
\hline \multirow{4}{*}{$\begin{array}{l}\text { C.Administrative } \\
\text { efficiency } \\
(8)\end{array}$} & C.1 Work Safety license & Assessment group evaluation type \\
\hline & C.2 Three simultaneous review & Assessment group evaluation type \\
\hline & $\begin{array}{l}\text { C.3Hidden danger rectification operation } \\
\text { mechanism }\end{array}$ & Assessment group evaluation type \\
\hline & C.4 Major hazards & Safety administrative statistics confirm type \\
\hline \multirow{7}{*}{$\begin{array}{l}\text { D. Supervisory effect } \\
(20)\end{array}$} & $\begin{array}{l}\text { D.1Mortality per } 100000 \text { people in mining } \\
\text { industry }\end{array}$ & Safety administrative statistics confirm type \\
\hline & D.2Mortality per one hundred million yuan & Safety administrative statistics confirm type \\
\hline & D.3Mortality per thousand vehicles & Safety administrative statistics confirm type \\
\hline & D.4Mortality per one million tons coal & Safety administrative statistics confirm type \\
\hline & D.5Listed supervisory completion & Safety administrative statistics confirm type \\
\hline & D.6 Public satisfaction & Public comment type \\
\hline & D.7 Enterprise satisfaction & Public comment type \\
\hline
\end{tabular}


Table 3. The comprehensive statistical results of performance evaluation indicator system of safety production supervision for local government

\begin{tabular}{|c|c|c|c|c|}
\hline \multirow[b]{2}{*}{ First-level indicator } & \multicolumn{4}{|c|}{ A total of indicator attribute } \\
\hline & $\begin{array}{l}\text { Secondary } \\
\text { indicator } \\
\text { number }\end{array}$ & $\begin{array}{l}\text { Safety } \\
\text { administrative } \\
\text { statistics confirm } \\
\text { type }\end{array}$ & \begin{tabular}{|l|} 
Assessment \\
group \\
evaluation type
\end{tabular} & $\begin{array}{l}\text { Public comment } \\
\text { type }\end{array}$ \\
\hline A.The construction of the supervision base & 8 & 7 & 1 & 0 \\
\hline B.Execution building & 21 & 12 & 9 & 0 \\
\hline C.Administrative efficiency & 4 & 1 & 3 & 0 \\
\hline D. Supervisory effect & 7 & 5 & 0 & 2 \\
\hline Total & 40 & 25 & 13 & 2 \\
\hline
\end{tabular}

Table 4. Contrast between four first-level indicators

\begin{tabular}{|c|c|c|c|c|c|c|c|}
\hline \multicolumn{2}{|l|}{ Item } & \multicolumn{2}{|c|}{$\begin{array}{l}\text { The construction of the } \\
\text { supervision base }\end{array}$} & \multicolumn{2}{|c|}{ Execution building } & $\begin{array}{l}\text { Administrative } \\
\text { efficiency }\end{array}$ & Supervisory effect \\
\hline \multicolumn{8}{|c|}{$\begin{array}{l}\text { The construction of } \\
\text { the supervision base }\end{array}$} \\
\hline \multicolumn{8}{|c|}{ Execution building } \\
\hline \multicolumn{8}{|c|}{$\begin{array}{l}\text { Administrative } \\
\text { efficiency }\end{array}$} \\
\hline \multicolumn{2}{|c|}{ Supervisory effect } & 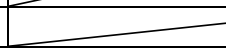 & & & $\infty$ & 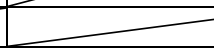 & 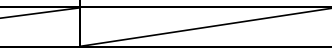 \\
\hline \multicolumn{8}{|c|}{$\begin{array}{l}\text { the results are presented using } 1 \sim 9 \text { and } \\
\text { reciprocal scaling comparison, } 1 \sim 9 \text { scales and } \\
\text { its reciprocal are shown in Table } 5 \text {. } \\
\text { Tai'an government officials compare four }\end{array}$} \\
\hline Scale & 1 & 3 & 5 & & 7 & 9 & $2,4,6,8$ \\
\hline Meaning & $\begin{array}{l}\text { The same } \\
\text { important }\end{array}$ & $\begin{array}{l}\text { A little more } \\
\text { important }\end{array}$ & $\begin{array}{l}\text { Obvio } \\
\text { impor }\end{array}$ & & $\begin{array}{l}\text { Highly } \\
\text { important }\end{array}$ & $\begin{array}{l}\text { Absolutely } \\
\text { important }\end{array}$ & $\begin{array}{l}\text { In the middle state of the } \\
\text { adjacent judgment }\end{array}$ \\
\hline
\end{tabular}

Table 6. Comparison results of indicator importance ratings

\begin{tabular}{|c|c|c|c|c|}
\hline & $A_{1}$ & $A_{2}$ & $\cdots$ & $A_{n}$ \\
\hline$A_{1}$ & $a_{11}$ & $a_{12}$ & $\ldots$ & $a_{1 n}$ \\
\hline$A_{2}$ & $a_{21}$ & $a_{22}$ & $\ldots$ & $a_{2 n}$ \\
\hline$\ldots$ & $\ldots$ & $\ldots$ & $\cdots$ & $\ldots$ \\
\hline$A_{n}$ & $a_{n 1}$ & $a_{n 2}$ & $\cdots$ & $a_{n n}$ \\
\hline
\end{tabular}

Judgment matrix has the following properties:

(1) $a_{i j}>0$;

(2) $a_{j i}=1 / a_{i j}$;

(3) $a_{i i}=1$.

c) Evaluation

The judgment matrix A is input to the matlab software, the largest eigenvalue of $\mathrm{A}$ and normalized feature vector are computed.

d) Consistency check
The consistency indicator is calculated using the formula $I_{C}=\frac{\lambda_{\max }-n}{n-1}$, where $\mathrm{n}$ is the order number of the judgment matrix. The consistency ratio, $R_{C}=\frac{I_{C}}{I_{R}}$, among which, $I_{R}$ needs to select from Table 7. The calculated RC should be below 0.1 . 
Table 7. The values table of mean random consistency indicator $I_{R}$

\begin{tabular}{|c|c|c|c|c|c|c|c|c|c|c|c|}
\hline & $n_{1}$ & 2 & 3 & 4 & 5 & 6 & 7 & 8 & 9 & 10 & $\cdots$ \\
\hline$I_{R}$ & 0 & 0 & 0.58 & 0.90 & 1.12 & 1.24 & 1.32 & 1.41 & 1.41 & 1.49 & $\ldots$ \\
\hline
\end{tabular}

When judgment matrix A meets the consistency, the corresponding eigenvector $U$ is calculated. The vector is called weight vector after resulting from the standardization, and each component of weight vector is the relative importance of the first-level indicator, namely the weight coefficient. The weight vector of the relative importance of each component is the first-level indicator, namely the weight coefficient.
The indicator weight coefficients obtained by analytic hierarchy process (AHP) are within the range of $(0,1)$, and the sum of the weight coefficient of every indicator is 1 . For the convenience of calculation, weight coefficient would be expanded 100 times, and then the weight scores of each indicator are achieved. First-level indicator weights are acquired according to this method, as shown in Table 8.

Table 8. Design of evaluation indicator weights

\begin{tabular}{|l|l|l|l|}
\hline First-level indicator & $\begin{array}{l}\text { Secondary indicator } \\
\text { number }\end{array}$ & Weight & $\begin{array}{l}\text { Average weight of secondary } \\
\text { indicator }\end{array}$ \\
\hline $\begin{array}{l}\text { The construction of the } \\
\text { supervision base }\end{array}$ & 8 & 19 & 2.375 \\
\hline Execution building & 21 & 53 & 2.524 \\
\hline Administrative efficiency & 4 & 8 & 2.000 \\
\hline Supervisory effect & 7 & 20 & 2.857 \\
\hline
\end{tabular}

are tested, the sum of weight scores of

\subsection{The determination method of weight score for secondary indicator}

The performance evaluation indicator system of safety production supervision for local government involves a lot of secondary indicators, it is difficult to make consistency check by using AHP, so Delphi method is adopted to design the weights of secondary indicators. The detailed calculation steps are as follows:

(a) Divide the weigh scores of first-level indicators by the total number of the corresponding secondary indicators, and the average score of

(b) Each secondary indicator is calculated.

(c) The retrieved effective questionnaires are designed in four important degree levels which are important, more important, and general and rejection, according to average score of the first step, four levels are set points respectively. When doing the questionnaires, experts give scores on the important degree.

(d) The questionnaires are statistical computed, average experts' score of each indicator is calculated, and then round to integer because the weight score must be an integer.

(e) The weighs of indicators finally determined secondary indicators included in the first-level indicator is equal to the first-level indicator weight, if it doesn't meet the conditions, the corresponding adjustment is made.

Finally the performance evaluation indicator system and weight score of work safety regulation for local government are acquired as shown in Table 9.

\section{Design of evaluation model}

Administration of production safety supervision effectiveness evaluation system, a total of 100 points, among them, 19 points, executive ability construction execution 53 points, 8 points, administrative efficiency supervision effect is 20 points.

According to the index of attributes, each relevant personnel or directly select points scored by the system statistics, or according to the evaluation criteria, in after the completion of the test statistics each secondary index score and is the evaluation scores.

Among them, $X_{Z}$ for total score, $X_{K}$ as the first $\mathrm{K}$ index score:

$$
X_{Z}=\sum_{K=1}^{40} X_{K}
$$


Table 9. The performance evaluation indicator system and weight score of work safety regulation

\begin{tabular}{|c|c|c|}
\hline First-level indicator & Secondary indicator & Weight score \\
\hline \multirow{8}{*}{$\begin{array}{l}\text { A. The construction of the } \\
\text { supervision base } \\
(19)\end{array}$} & A.1 Organizational architecture & 2 \\
\hline & A.2 Special fund & 2 \\
\hline & A.3 Regulatory funds and equipment & 3 \\
\hline & A.4 Regulatory team construction & 3 \\
\hline & A.5 Performing duties & 3 \\
\hline & A.6 Enterprise standardization & 3 \\
\hline & A.7 Occupational hazards declaration & 2 \\
\hline & A.8 Activities establishment situation & 1 \\
\hline \multirow{21}{*}{$\begin{array}{l}\text { B. Execution building } \\
(53)\end{array}$} & B.1Conducting annual activities situation & 2 \\
\hline & B.2 Hold meetings situation & 2 \\
\hline & B.3 The responsibility system & 4 \\
\hline & B.4 Cadres performance evaluation & 2 \\
\hline & B.5Governance of illegal rule violations & 3 \\
\hline & B.6 Close enterprises situation & 3 \\
\hline & B.7Major festivals and time arrangement & 3 \\
\hline & B.8 Special project rectification & 3 \\
\hline & B.9 Work safety month & 4 \\
\hline & B.10 Safety culture propaganda & 2 \\
\hline & B.11 Employee training & 2 \\
\hline & B.12Head,management personnel training & 2 \\
\hline & B.13Emergency rescue command system & 2 \\
\hline & B.14 Contingency plan management & 2 \\
\hline & $\begin{array}{l}\text { B. } 15 \text { Work safety emergency information construction and basic data } \\
\text { updating }\end{array}$ & 4 \\
\hline & B.16 Law enforcement plan & 2 \\
\hline & B.17 Dynamic regulation & 2 \\
\hline & B.18Supervising enterprises establishing rules & 2 \\
\hline & B.19 Supervising institutions and the staff setting of enterprises & 2 \\
\hline & B.20 Supervising enterprises safety costs & 2 \\
\hline & B.21 Yellow card warning & 3 \\
\hline \multirow{4}{*}{$\begin{array}{l}\text { C. Administrative efficiency } \\
(8)\end{array}$} & C.1 Work Safety license & 2 \\
\hline & C.2 Three simultaneous review & 2 \\
\hline & C.3Hidden danger rectification operation mechanism & 2 \\
\hline & C.4 Major hazards & 2 \\
\hline \multirow{7}{*}{$\begin{array}{l}\text { D. Supervisory effect } \\
(20)\end{array}$} & D.1Mortality per 100000 people in mining industry & 3 \\
\hline & D.2 Mortality per one hundred million yuan & 3 \\
\hline & D.3 Mortality per thousand vehicles & 3 \\
\hline & D.4 Mortality per one million tons coal & 3 \\
\hline & D.5 Listed supervisory completion & 3 \\
\hline & D.6 Public satisfaction & 3 \\
\hline & D.7 Enterprise satisfaction & 2 \\
\hline
\end{tabular}

\section{Empirical research}

According to the above safety regulation performance evaluation index system and model, this study used questionnaire Tai'an in Shandong province city of production safety supervision department for the performance evaluation. Assessment process includes: set up assessment team; to form a panel; determine the sampling personnel, training personnel; Questionnaires; Recycling questionnaire; the questionnaire on statistics and analysis. The poll gave out 78 copies of questionnaires, back to 65 . Test result is as the following Table 9 and Table 10. 
Table 9. Primary index scores

\begin{tabular}{|l|l|l|}
\hline First grade assessment indicator & Score & Full score \\
\hline Safety supervision organs & 16.8 & 19 \\
\hline construction of Administrative capacity & 29.8 & 53 \\
\hline Executive efficiency & 6.4 & 8 \\
\hline Supervision efficiency & 18.2 & 20 \\
\hline
\end{tabular}

Table 10. Secondary index scores

\begin{tabular}{|l|l|l|}
\hline Second level evaluation index & Score & Grade \\
\hline A. 1 Organizational architecture & 3.00 & excellent \\
\hline A. 2 Special Fund & 2.00 & excellent \\
\hline A. 3 Funds and equipment & 3.00 & excellent \\
\hline A. 4Staff team-building & 2.50 & medium \\
\hline A. 5Due diligence system & 2.00 & good \\
\hline A. 6 Quality standard construction. & 1.50 & medium \\
\hline A. 7Occupational hazards report & 1.00 & medium \\
\hline A. 8Activities create & 1.50 & medium \\
\hline A. 9Conduct meetings, & 1.00 & poor \\
\hline A. 10 Accountability systems & 3.00 & good \\
\hline A. 11Crack down on speculation & 2.00 & medium \\
\hline A. 12 Close illegal enterprises & 2.00 & medium \\
\hline A. 13 How to arrange major festivals and holidays & 1.2 & poor \\
\hline
\end{tabular}

Among them, System test total score 65 points, excellent index number to 10 , good indicator number is 2 , medium index number for 22, poor index number is 6. Comprehensive assessment results for the medium.

\section{Conclusions}

Performance evaluation of work safety regulation for local government can achieve the objective evaluation of the government safety regulation situation, the advantages and disadvantages of government work safety regulation can be found out, which can provide reference to government work safety supervision. It is conducive to improve work safety regulation performance of local government, and then enhance the overall operating efficiency of the government. This study constructs a performance evaluation system of work safety regulation for local government based on balanced score card method, designs a performance evaluation indicator system of work safety regulation for local government suitable for city and county level. The factors affecting work safety regulation performance of local government are analyzed systematically, according to the combination of qualitative and quantitative method, a multi-level and complex problem is made a systematic and hierarchical analysis. In practical application, the indicator system should be adapted to the changing of national policy and the government safety regulation level continuously. In addition, performance evaluation of work safety regulation for local government is meaningful with rewards and punishment; otherwise it can't play an incentive role.

\section{References}

Luo Yun. The construction and optimization of work safety regulation mode in China. Modern Occupational Safety, 2014(1): p36-38.

Luo Yun, LiXin, Cui Gang. The theory and method of government safety regulation performance evaluation. 2010 academic essays of China association of occupational safety and health: p16-25.

Chu Dejiang. The present situation and foresight of the local government performance evaluation indicator system research. Journal of Beijing Administrative College, 2008(1): p17-21. 
Chen Tianxiang, Fu Lin. Research on the performance measurement of government's supervision on the coal mine safety production. Journal of Xiangtan University(Philosophy and Social Sciences), 2009(5): p18-21.

Wang Yonggang, Lin Zhixiao, Chen Daogang, Zheng Hongyun. Research on the evaluation model of the performance of the civil aviation safety supervision and management bureau based on balance score card. Safety and environmental engineering, 2013(4): p132-135.

Dong Zhengliang, Wang Fangning, Guo Qiming etc. The construction of safety performance management system based on the balanced score card. Industrial Safety and Environmental Protection,2007(11): p57-59.

Shan Guoqi,Shen Feng. Empirical study on the performance evaluation system of enterprises based on balanced score card. Science and Technology Management Research, 2010(16): p243-246.

Sun Yuqian. The method and system development for performance evaluation of government comprehensive supervision for safety production. China University of Geosciences (Beijing), 2015 